SYNIHITIC THROMBUS MODEL FOR IN VITRO

STUDIJS OF LAASER THROVBOLYSIS

RECEIVED

\author{
JUL 011998
}

OSTI

Robert E. Hermes and Keti Trajkovska

Materials Science \& Technology Division, MST-7

Los Alamos National Laboratory

DISTIIBUTION OF THS DOCLMENT IS UNHITED

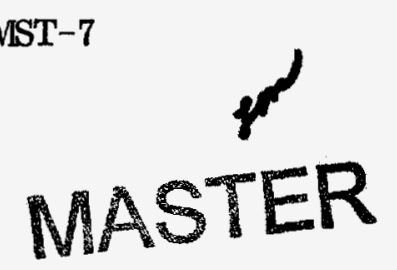

Submitted to:

SPIE Proceedings Vol. 3254A paper\# 28

Conference Chair: Steven Jaques (OMLC)

SPIE Bios 98

24-30 January, 1998

San Jose Convention Center, San Jose, CA

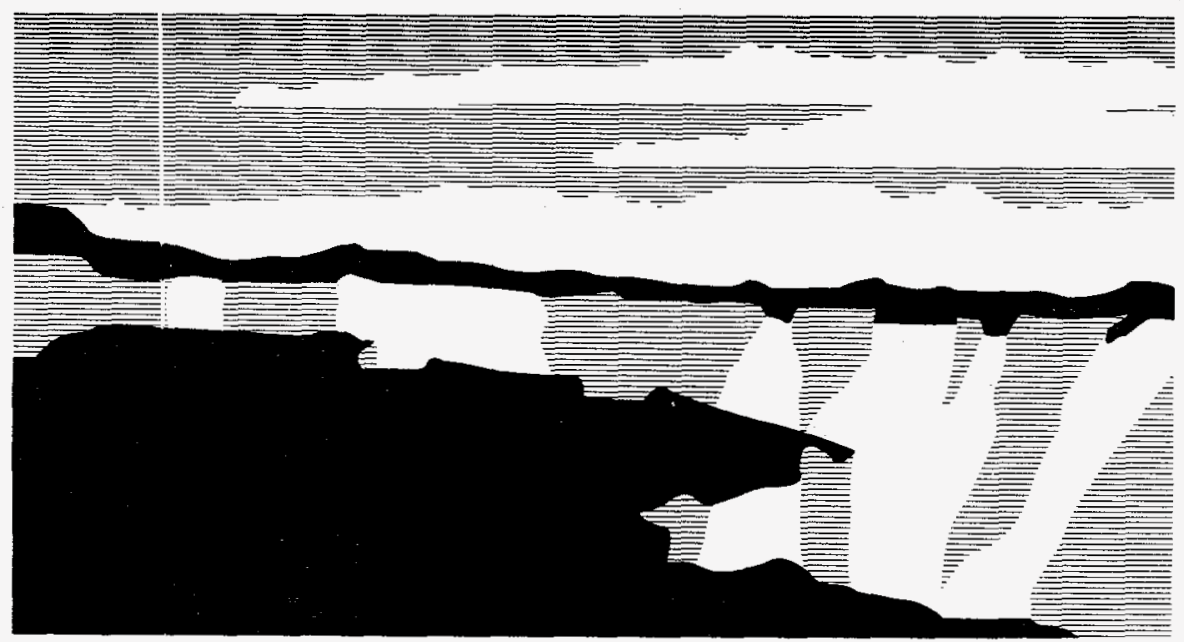

NATIONAL LABORATORY

Los Alamos National Laboratory, an affirmative action/equal opportınity emplóyer, is operated by the University of California for the U.S. Department of Energy under contract W-7405-ENG-36. By acceptance of this article, the publisher recognizes that the U.S. Government retains a nonexclusive, royalty-free license to publish or reproduce the published form of this contribution, or to aliow others to do so, for U.S. Government purposes. The Los Alamos National Laboratory requests that the publisher identify this anticle as work performed under the auspices of the U.S. Department of Energy. 


\section{DISCLAIMER}

This report was prepared as an account of work sponsored by an agency of the United States Government. INeither the United States Government nor any agency thereof, nor any of their employees, makes any warranty, express or implied, or assumes any legal liability or responsibility for the accuracy, completeness, or usefulness of any information, apparatus, product, or process disclosed, or represents that its use would not infringe privately owned rights. Reference herein to any specific commercial product, process, or service by trade name, trademark, manufacturer, or otherwise does not recessarily constitute or imply its endorsement, recommendation, or favoring by the United States Government or any agency thereof. The views and opinions of authors expressed herein do not necessarily state or reflect those of the United States Government or any agency thereof. 


\section{DISCLAIMER}

Portions of this document may be illegible electronic image products. Images are produced from the best available original document. 


\title{
Synthetic thrombus model for in vitro studies of laser thrombolysis
}

\author{
Robest E. Hermes and Keti Trajkovska \\ Los Alamos National Laboratory, MST-7 @ E549, Los Alamos, NM 87545 USA
}

\begin{abstract}
Laser thrombolysis is the controlled ablation of a thrombus (blood clot) blockage in a living arterial system. Theoretical modeling of the interaction of laser light with thrombi relies on the abi ity to perform in vitro experiments with well characterized surrogate materials. A synthetic thrombus formulation may offer more accurtte results when compared to in vivo clinical experiments. We describe here the development of new surrogate materials based on formulations incorporating chicken egg, guar gum, modified food starch, and a laser light absorbing dye. The sound speed and physical consistency of the materials were very close to porcine (arterial) and human (venous) thrombi. Photographic and videotape recordings of pulsed dye laser ablation experiments under various experimental conditions were used to evaluate the new material as compared to in vitro test; with human (venous) thrombus. The characteristics of ablation and mass removal were similar to that of real thrombi, and therefore provide a more realistic model for in vitro laser thrombolysis when compared to gelatin.
\end{abstract}

Keywords: thrombolysis, laser, gelatin, egg, thrombus, guar, starch

\section{INTRODUCTION}

A Cooperative Research and Development Agreement (CRADA) between the Los Alamos National Laboratory (operated by the University of California), the Oregon Medical Laser Center [OMI,C] (Providence St. Vincent Hospital and Medical Center, Portland, OR) in association with Palomar Medical Technologies ${ }^{1}$ (Bevirly, MA) was established to provide an understanding of the fundamental mechanism(s) responsible for effective laser thrombolvsis. Theoretical calculations were performed by several other team members, ${ }^{2-5}$ which used input from experiments performed at the Cregon Medical Laser Center, ${ }^{2}$ and the gelatin experiments described here.

As the materials science part of the multidisiplinary laser thrombolysis team, we developed surrogates which were used in the in vitro laser thrombolysis experiments described below. Although our main objective was to reproduce the gelatin/dye mixture used at the Oregon Medical Laser Center, ${ }^{2}$ we also provided the important material properties needed by the team members responsible for the theoretical code development. They were primarily interested in the density and the speed of sound through the material. Their work relied upon the gelatin/dye material as being the most convenient choise for simplifying the parameters in the initial theoretical code development. However, the gelatin/dye material neither had the appearance of, nor behaved like a thrombus under the conditions established in our in vitro laser thrombolysis studies.

We realized there would eventually be a need for a moce complex surrogate that would have the general physical characteristics of a real thrombus, and behave similarly under the laser thrombolysis conditions studied here. One practical requirement was that the material had to be stable enough to withstand several minutes under water (and contrast fluid), without breaking up or dissolving. After several unsuccessful attempts at using crosslinking agents for the gelatin/dye mixture, we began investigating several other bioderived gums such as xanthan, guar, and acacia in combination with egg whice (both powdered and liquid), egg yolk, and/or gelatin. Interestingly, we found that one of our best surrogate materials (a combination of gelatin, egg yolk and red dye), was irreproducible in that chicken eggs obtained from New Mexico worked fine, but those obtained in Oregon did not set up under the conditions established in New Mexico.

\section{EXPERIMENTAL}

\subsection{Materials}

Regular tap water was used where indicated. The X-ray contrast fluid MD-76 from Mallinckrodt Medical, Chesterfield, MO, was kindly provided to us by the Oregon Medical Laser Center, and diluted 1:1 with tap water prior to use. Porcine gelatin, $\sim 175$ bloom, and gum guar were used as received from Aldrich Chemical Company, Milwaukee, WS. Normal octane was purchased from J. T. Baker Chemical Company, Phillipsburg, NJ, and the mineral oil (USP) 'was obtained from Paddock Laboratories, Inc., Minneapolis, MN. The laser energy absorbing Direct Red 81 dye was obtained from Sigma Chemical Company, St. Louis, MO. The laser dye Rhodamine 575 was used as received from Exciton Chemical Company, Dayton, OJ. Grade AA chicken eggs were purchased at the local grocery store. The 1-cm path length plastic cuvettes (clear path on all four sides), and polypropylene disposable pipets were obtained from VWR Scientific, San Francisco, CA. Vanilla flavored JELLO ${ }^{\circledast}$ Stir 'n Snack ${ }^{\text {rM }}$, Kraft Foods, Inc., White Plains, NY, was purchased at the local grocery store. This latter component is comprised of sugar, modified :ood starch, sodium phosphates (for thickening), glycerine, salt, polysorbate 60 , artificial color, artificial flavor, yellow 5 , yellow 6 , and natural flavors in undetermined amounts. The human thrombus was obtained by drawing venous blood into a siliconized tube and allowing the blood clot to coagulate at close to body temperature. 


\subsection{Sample Preparation}

Gelatin/dye samples were prepared from the formulation previously developed at OMLC. ${ }^{2}$ Porcine gelatin (3.5 grams) was gradually added to rapidly stirred boiling water (100 milliliters) in a 250 milliliter capacity beaker until dissolved. Upon cooling, clear gels were prepared by carefully pipetting the liquid into cuvettes to a level of about half full, then refrigerated for about 30 minutes for gellation to occur. The gelatin/dye mixture was prepared similarly, except Dirsct Red 81 ( 0.15 grams) was added during the mixing step. Hot water was introduced to the top of each cold gel and placed into a freezer for a few minutes. When decanted and rinsed with cold water, this had the effect of leveling the gel in each cuvette by removing the minis zus. This was important in order to obtain acceptable electronic photographs through the cuvette. These samples were also used as the base material for the other samples. The gelatin/dye mixture was added to a level of approximately 1 millimeter on top of the clear gel, and refrigerated. This is called OMLC clot in the photographs.

The surrogate thrombus was prepared by mixing vanill a flavored JELLO ${ }^{\odot}$ Stir 'n Snack ${ }^{\mathrm{TM}}$ ( 8.0 grams) with gum guar (3.0 grams), Direct Red 81 dye (1.0 gram) and the contents of one chicken egg ( 51 grams, 50 milliliters). This mixture was blended for $30-40$ seconds in a stainless-steel cup, using the low speed position on a W'aring ${ }^{\text {TM }}$ blender. Pipetting was performed immediately because of the fast set-up time of this mixture. One or two drops were carefully introduced to the flattened top of the clear gels, and refrigerated. This sample type is called LANL clot in the photographs.

The human thrombus was carefully sliced into several samples ( 2 millimeter thick) having a radial diameter of 1 centimeter. These were rinsed with water just prior to placing them on the surface of the clear gels used for the experiments. These are called Venous Clot in the photographs.

\subsection{Apparatus Description}

A Palomar Medical Technologies Model 3010 dye lase was kindly provided by Palomar, ${ }^{1}$ and was equipped with a fiber optic delivery device (multimode fiber, 300 micron diameter). We used Rhodamine 575 laser dye and the appropriate laser controls to deliver 50-mJ from the fiber tip in a single shot mode. The tip was general.y centered in the cuvette, and held to 1 millimeter above the test surface. The pulsewidth (FWHM) was nominally 1-microsecond (system specifications, not measured). A 400 milliwatt continuous wave doubled Nd:YAG Verdi'M laser, Coherent Laser Group, Santa Clara, CA, was used for back illumination of the samples during each experiment. Time resolved images were obtained with a gated electronic framing camera, model 486, Hadland Photonics, Cupertino, CA, with each frame having an exposure time of 500 nanoseconds. The first frame was timed close to the laser pulse and considered to be $\mathrm{T}=0$. The other seven frames were recorded at the following times: $25,90,100,150,300,500$, and 800 microseconds. A data set of eight images was obtained for each laser pulse. Experiments were run in triplicate with each test material, but in a different location for each shot. Each test was also videotaped through a magnifying lens using a videocassette recorder connected to a camera.

\subsection{Laser Thrombolysis Experimental Procedure}

The test cuvettes were removed from refrigeration, and allowed to reach room temperature prior to each experiment. In each case, the test liquid was added to the top of the solidified material wi hin a few minutes of testing. The cuvette was placed into a special holder while the fiber optic tip was adjusted to 1 millimeter from the surface of the test material. The laser and camera were simultaneously triggered to obtain the laser thrombolysis record.

\section{RESULTS AND DISCUSSION}

Throughout these experiments, we attempted to provide time-resolved data that demonstrates the utility of our new synthetic thrombus model for in vitro laser thrombolysis. The driving factor was the need to evaluate several operational conditions using liquids of various density above the samples. The liquids were chosen frc $m$ those previously studied at OMLC: water, 1:1 mixture of MD-76:water, and mineral oil. Addtitionally, we tried octane, which has a lower density and much lower boiling point than that of mineral oil. The differences in the bubble dynamics obtained with each liquid and $\mathrm{m}$ atrix were to be evaluated and emulated using the data for the theoretical calculations. As materials scientists, we were attempting to answer the questions - can we make a material that is stable enough to withstand several liquids? have the look and feel of a "standard" thrombus? and will the surrogate perform under laser thrombolysis conditions similar to that of a real thrombus? The examples shown in this paper were chosen to address these issues.

\subsection{Description of Figures}

The figures on the following pages were taken from the data files generated by the Hadland camera. They are viewed starting from the first frame in the top left corner, then down to frame two, ba:k up and to the right for frame three, then down, and repeating until frame eight is on the far bottom right. For simple comparison, three photographs are included in each figure, with the OMLC Clot on top, the LANL Clot in the middle, and the Venous Clot on the bottom. In all cases, we compared the first two sets of photographs with the results obtained from the laser thrombolysis of the Venous Clot. Figure 1 shcws the first set having water on top. Figure 2 shows the 1:1 MD-76:water. Figure 3 shows mineral oil, and figure 4 shows octane. Observalions include the size of the bubble in each respective time frame (generally 2-5), and whether jetting of material occurs at similar times in the sequence (usually frames 6-8). The OMLC Clot data shows typical behavior for bubble formation and collapse, and conveniently includis a visually acceptable view of the bubble below the surface. Unfortunately, the others do not display such behavior, even though the test material was also prepared on top of the clear gelatin. 
Figure 1. in vitro laser thrombolysis using OMLC, LANL, and Venous Clot materials under water

\section{OMLC clot}

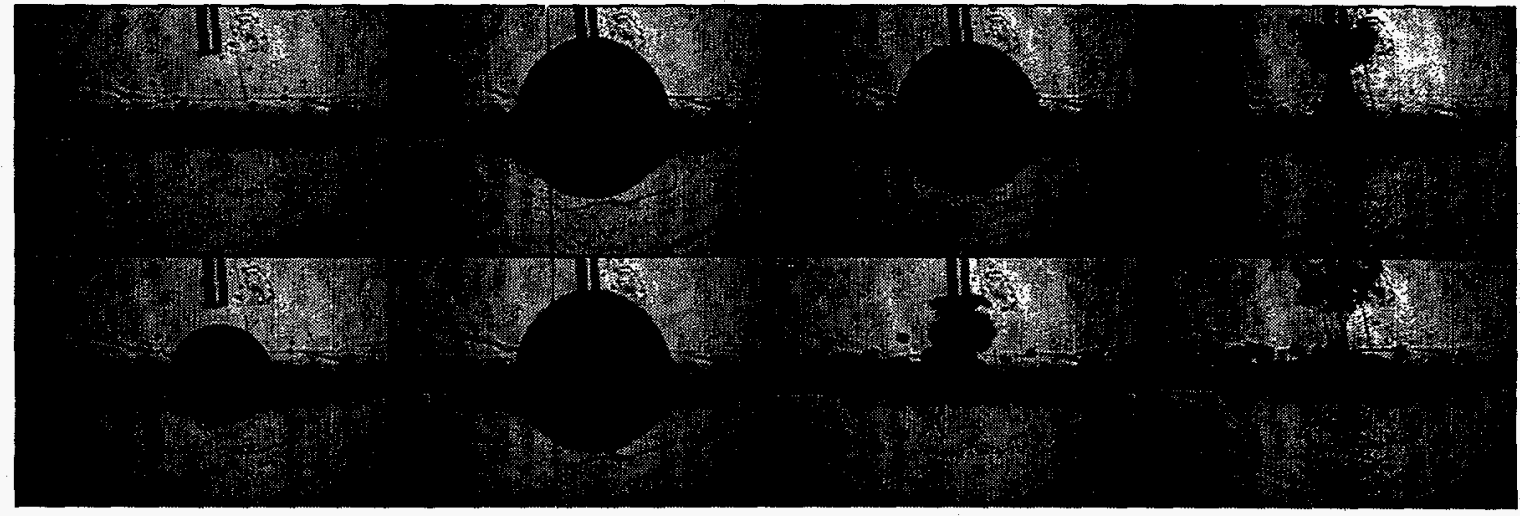

LANL clot

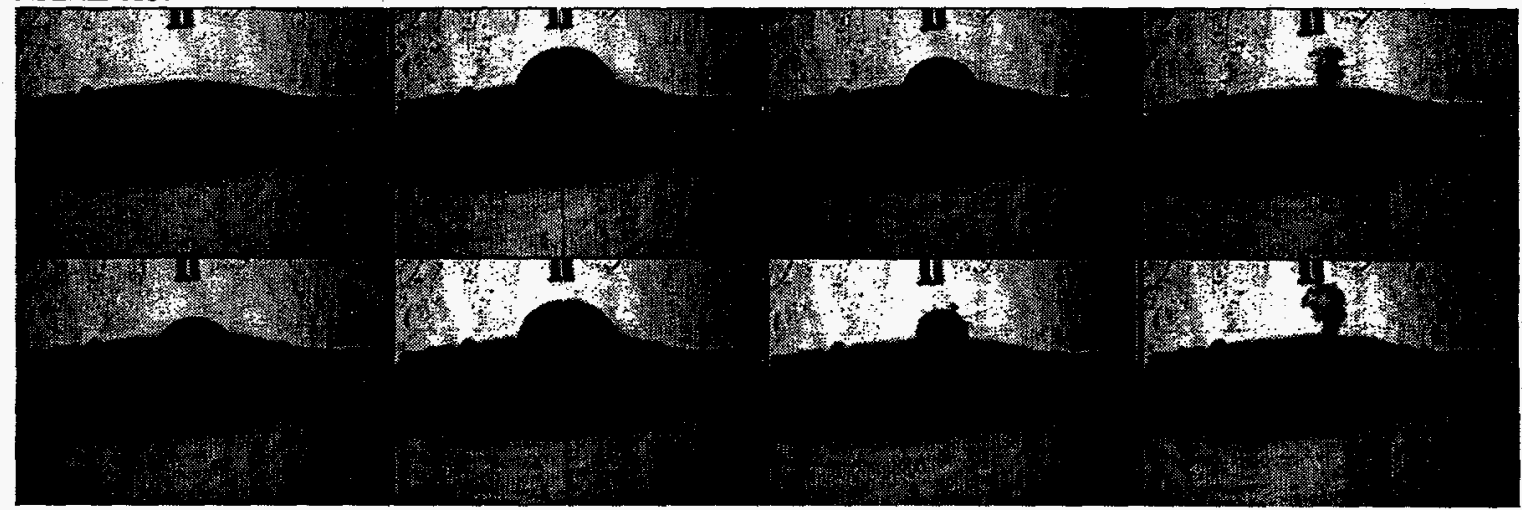

Venous clot

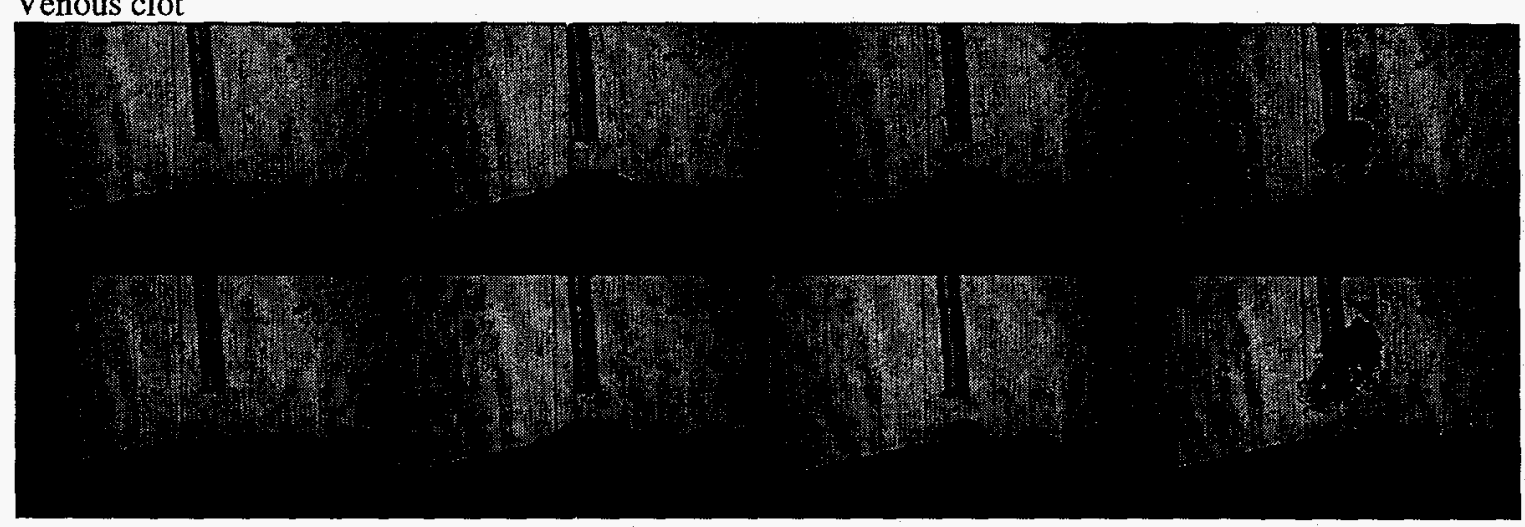


Figure 2. in vitro laser thrombolysis using OMLC, LANL, and Venous Clot materials under MD-76:water
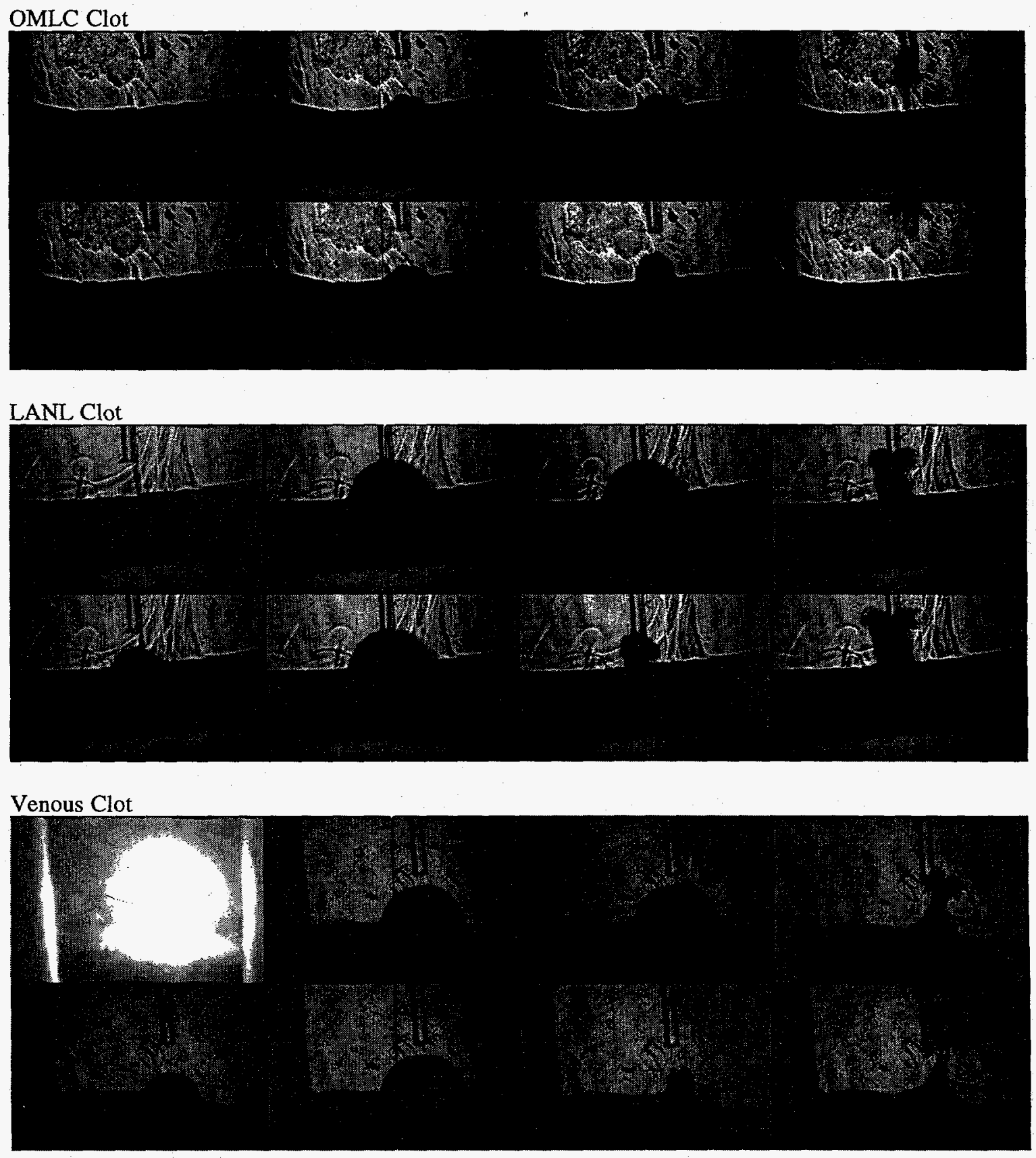
Figure 3. in vitro laser thromboly'sis using OMLC, LANL, and Venous Clot materials under mineral oil

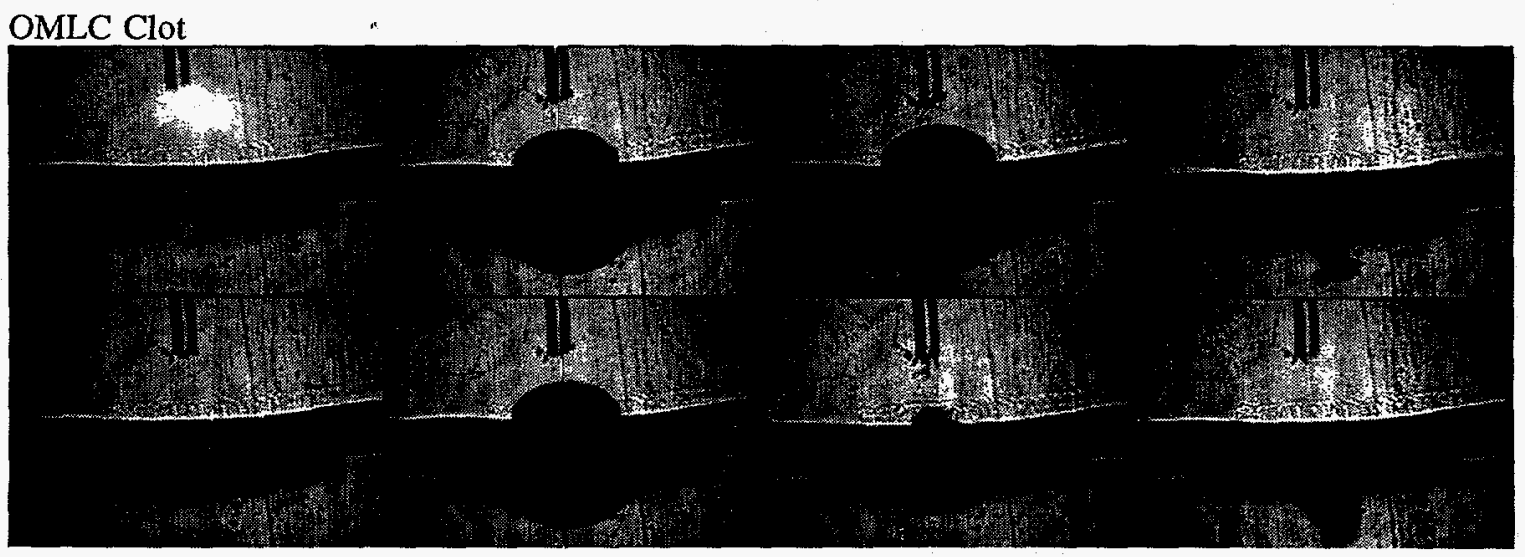

LANL Clot

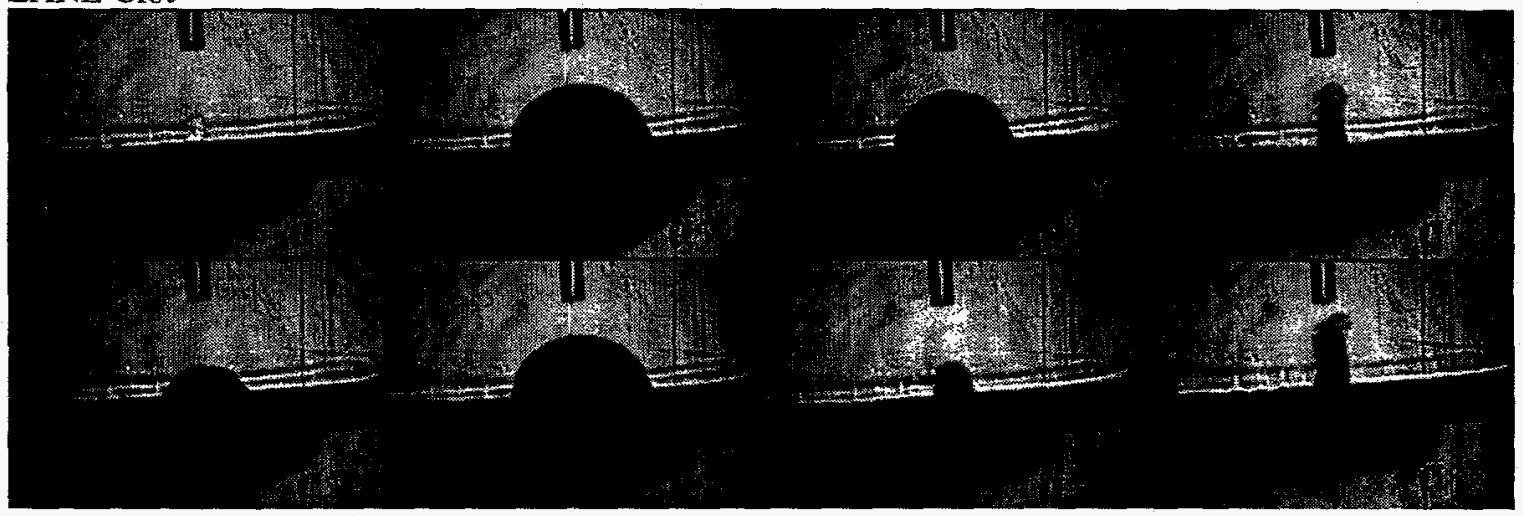

Venous Clot

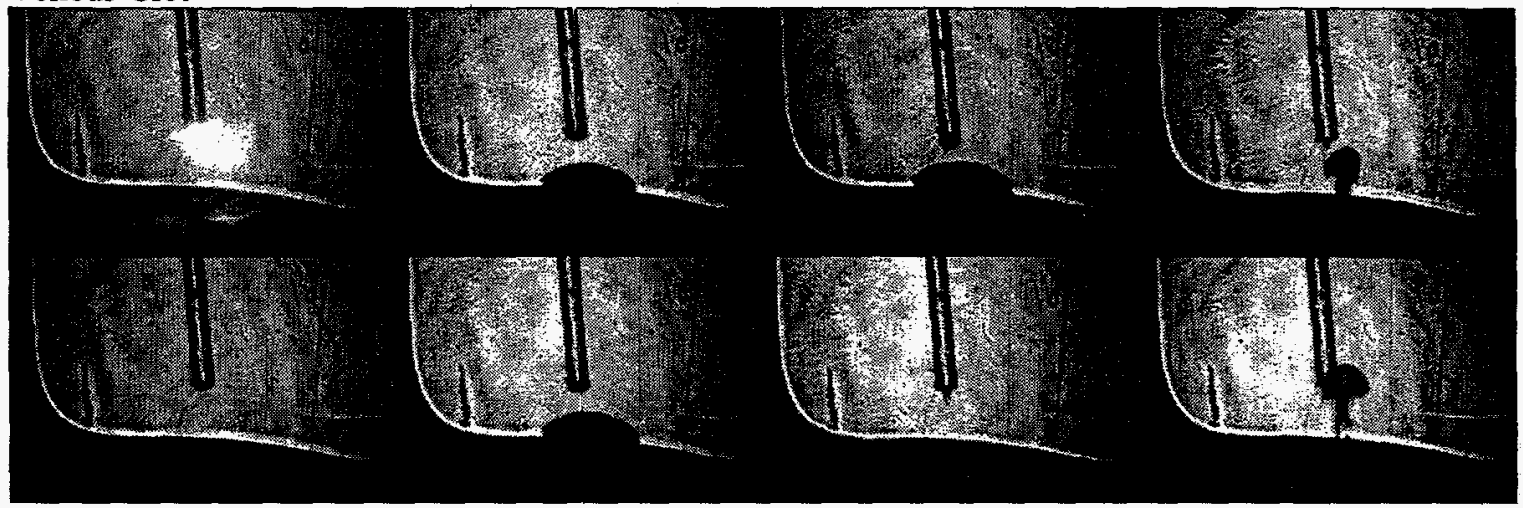


Figure 4. in vitro laser thrombolysis using OMLC, LANL, and Venous Clot materials under octane
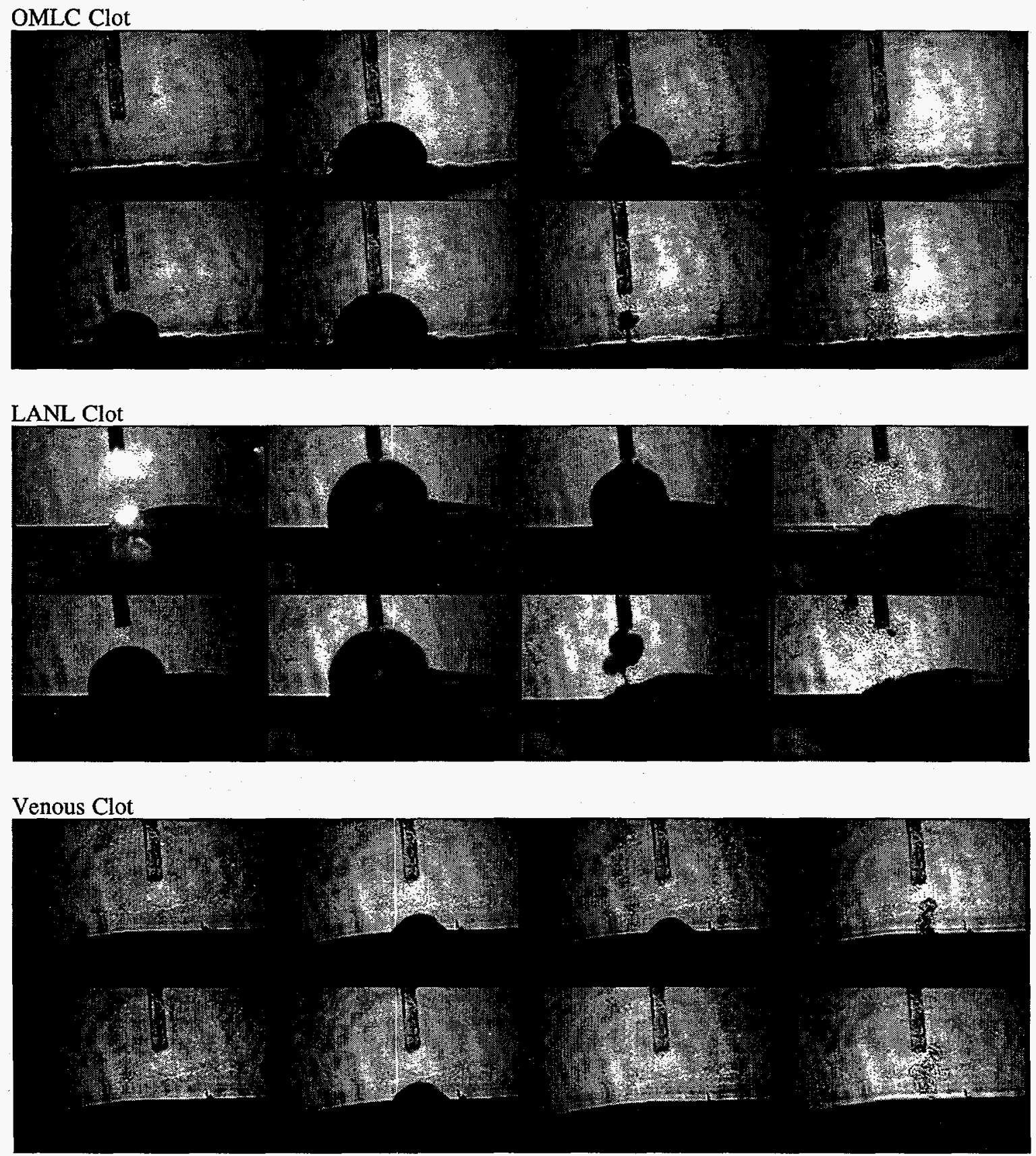


\section{RESLILTS AND DISCUSSION, continued}

\subsection{Under water}

In Figure 1, a comparison between all three clots show's a great similarity between the apparent diameter of the bubble in the LANL Clot and the Venous Clot, especially in frames 3-6. However, the bubble on the Venous Clot is somewhat obscured by the surface facing the camera, and makes for a difficult measurement. A nice particulate jet is evident in the last frame of the Venous Clot, as well as the LANL Clot. The OMLC Clot shows the typical behavior in a uniform system.

\subsection{Under MD-76:water}

This was perhaps the most important series because Figure 2 was performed with the conrast fluid used in in vivo laser thrombolysis experiments. The bright flash in frame 1 of the Venous Clot was due to the framing camera catching the laser pulse. It is clear that the performance of the LANL Clot is virtually identical to that of the Venous Clot. Although it may not be perfect, this result was the best we have ever witnessed.

\subsection{Under mineral oil}

Figure 3 displays a unique phenomenon, particularly when comparing the OMLC Clot and the LANL Clot. Although the density of mineral oil is below that of both materials, one can clearly see that the jet reverses direction in the OMLC Clot (into the gel matrix), and appears to provide a normal direction for the ejecta in the LANL Clot. Apparently, the majority of the bubble in the OMLC Clot was below the interface, and just the opposite in the LANL Clot. The good news was that the ejecta in the Venous Clot was also above the interface.

\subsection{Under n-octane}

Figure 4 proved to be very interesting. Hardly any res\}onse was observed for the Venous Clot but it still produced a jet. The LANL Clot had a much larger bubble formation, and was shown to blow expanding microbubbles, as evident in the change from frame 7 to frame 8 . Both the OMLC Clot and the LANL Clot displayed raslically different behavior when compared with the Venous Clot.

\section{CONCLUSIONS}

After several iterations of trying to make a synthetic thombus material that looks, feels, and performs like a real venous thrombus (Venous Clot) under in vitro laser thrombolysis, we believe we liave succeeded in preparing a simple mixture that met the performance criteria established by the experimental procedures studied her:. In particular, the performance of the LANL Clot was nearly identical to that of the Venous Clot, expecially under the contrast fluid. The results achieved under mineral oil and octane are left for the theoretical types to ponder. The authors recognize that a Venous Clot is not the best model for the thrombi usually associated with coronary disease or stroke.

\section{ACKNOWLEDGEMENTS}

The authors gratefully acknowledge the assistance of S cott Prahl of OMLC in helping to define the scope of our work. We also thank U Sathyam and H. Shangguan for their expert knowledge in the preparation of the OMLC gelatin/dye surrogate. Alan Shearin and Henry Aldag of Palomar were instrumental in providing both lechnical assistance and the laser used for these experiments. Dennis Paisley and David Stahl of Los Alamos National Laboratory were responsible for the optical set-up and laser testing, without which our experiments could not have been performed.

This CRADA was supported by the U.S. Department of : Energy under Contract W-7405-ENG-36.

\section{INOTES AND REFERENCES}

1. The medical laser division of Palomar Medical Technologies, Inc. has recently been purchased by Physical Sciences Inc., Andover, MA.

2. U. S. Sathyam, A. Shearin, E. A. Chasteney, and S. A. Prahl, "Threshold and Ablation Efficiency Studies of Microsecond Ablation of Gelatin Under Water," Lasers in Surgery and Medic ne 19, 397, 1996.

3. E. J. Chapyak, R. P. Godwin, S. A. Prahl, and H. Shingguan, "A comparison of numerical simulations and laboratory studies of laser thrombolysis," in SPIE Proceedings of Diagnostic and Therapeutic Cardiovascular Interventions VII , K. Gregory, ed., Vol. 2970A, presented at Bios'97, February 1997, San Jose, CA, SPIE, Bellingham, WA.

4. R. P. Godwin, E. J. Chapyak, S. A. Prahl, and H. Shingguan, "Laser mass ablation efficiency measurements indicate bubble-driven dynamics dominates laser thrombolysis," in SPIE Proceedings of Diagnostic and Therapeutic Cardiovascular Interveentions-VIII, K. Gregory, ed., Vol. 3245A, presented at Bios'98, January 1998, San Jose, CA, SPIE, Bellingham, WA.

5. E. J. Chapyak and R. P. Godwin, "Physical mechani:ms of importance to laser thrombolysis," in SPIE Proceedings of Diagnostic and Therapeutic Cardiovascular Interventions-VIII, K. Gregory, ed., Vol. 3245A, presented at Bios'98, January 1998, San Jose, CA, SPIE, Bellingham, WA. 


\section{Vu-Graphs Follow for:}

TITLE: Synthetic Thrombus Model for in vitro Studies of Laser Thrombolysis.

AUTHORS: $\quad$ Robert E. Htrmes and Keti Trajkovska Los Alamos National Laboratory

Group MST.7, Mail Stop E549

Los Alamos, NM 87545

(505) 667-681i2, Fax (505) 667-8109

e-mail: hermes@lanl.gov 
BIOS ‘98 International Biomedical Optics Symposium Laser-Tissue Interaction IX

Paper 3254A28

\section{Synthetic thrombus model for in vitro studies of laser thrombolysis}

Robert E. Hermes and Keti Trajkovska

Los Alamos National Laboratory

MST-7@E549

Los Alamos, NM 87545 USA

hermes@lanl.gov

Cooperative Research And Development Agreement

between

Oregon Medical Laser Center

Palomar Medical Technologies, Inc. and Los Alamos National Laboratory 
- Laser Thrombolysis

- OMLC Experiments

- LANL Experiments

- Conclusions 


\section{Laser Thrombolysis:}

\section{ablation of thrombi \\ (blood clots)}

\section{using a fiber optic \\ coupled dye laser}

\section{Vapor expansion}

Fluid flow catheter bubble

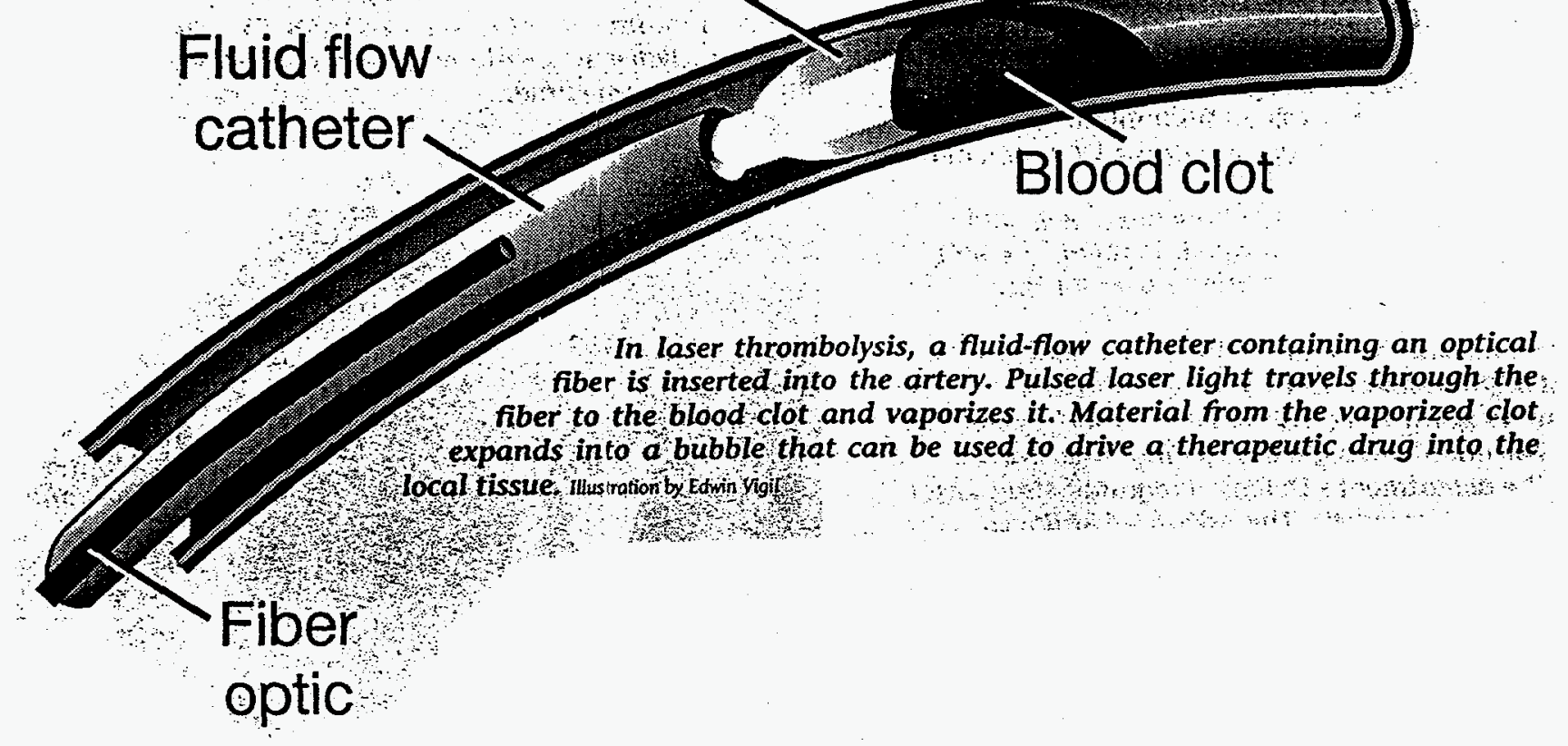




\section{thrombus surrogates}

Requirements

- easily prepared

- property evaluations

- stable under a variety of liquids (water, organics) 

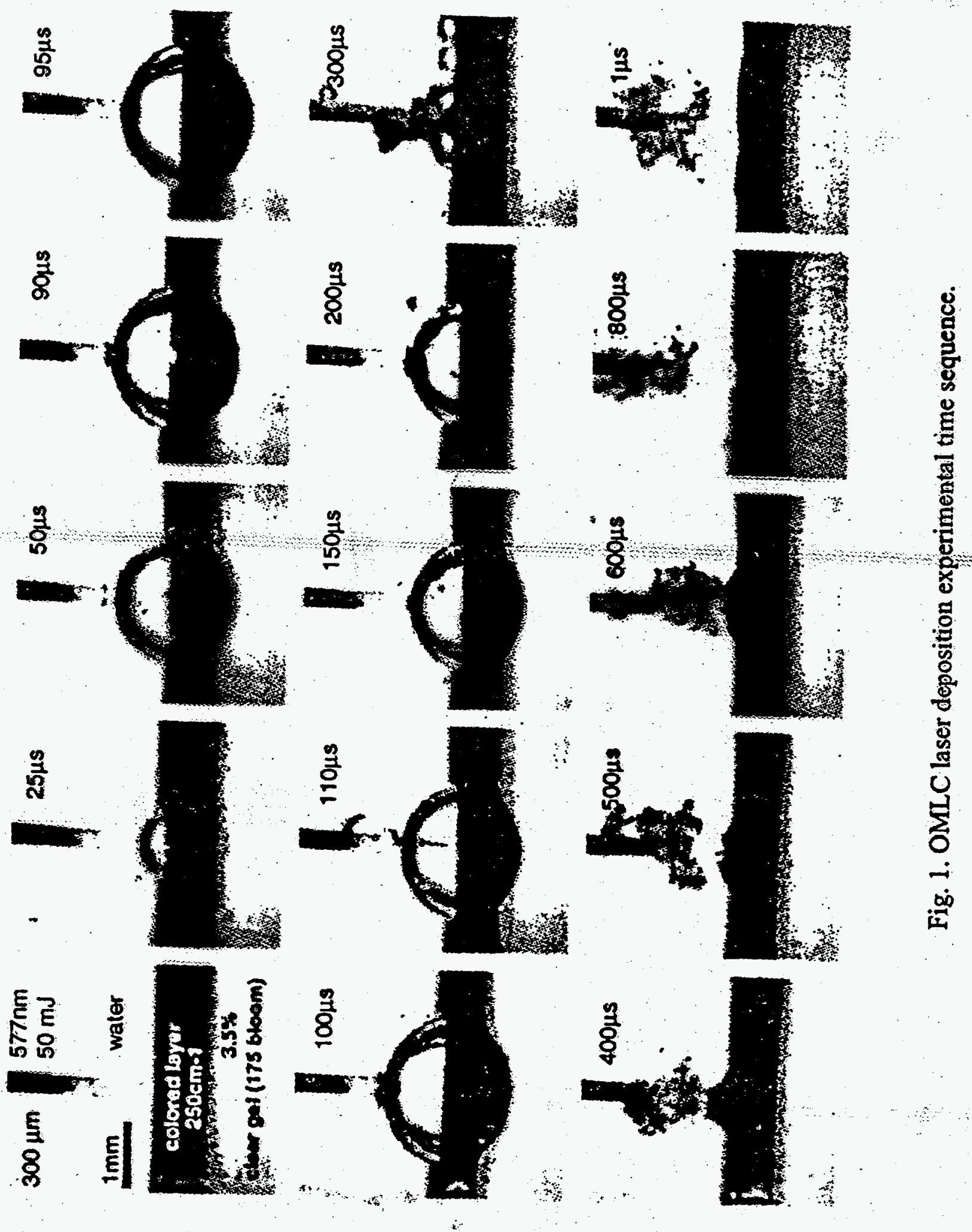


\section{thrombus surrogates}

OMLC Clot Composition

$3.5 \%$ porcine gelatin (175 bloom)

$0.15 \%$ Direct Red \#81 dye

remainder is tap water

- easily prepared

- property evaluations

- semi-stable under a

variety of liquids 


\section{thrombus surrogates}

\section{LANL Clot Composition}

1996 gelatin, dye, whole egg

...problems

1997 8.0 gm JELLO ${ }^{\circledR}$ Stir 'n Snack $^{\mathrm{TM}}$

$1.0 \mathrm{gm}$ Direct Red \#81 dye

$3.0 \mathrm{gm}$ Gum Guar

$1 \mathrm{Lg} . \operatorname{Egg}(\sim 51 \mathrm{gm}, \sim 50 \mathrm{~mL})$

- easily prepared

- property evaluations

- very stable under a variety of liquids 


\section{Laser Thrombolysis}

- Palomar 3010 dye laser

- 300 micron fiber optic

- $50 \mathrm{~mJ} /$ pulse (average)

- 1.0 microsec. (FWHM)

- $1.0 \mathrm{~mm}$ above surface of surrogate thrombus

- Liquids: water

MD-76:water 1:1

mineral oil

n-octane 


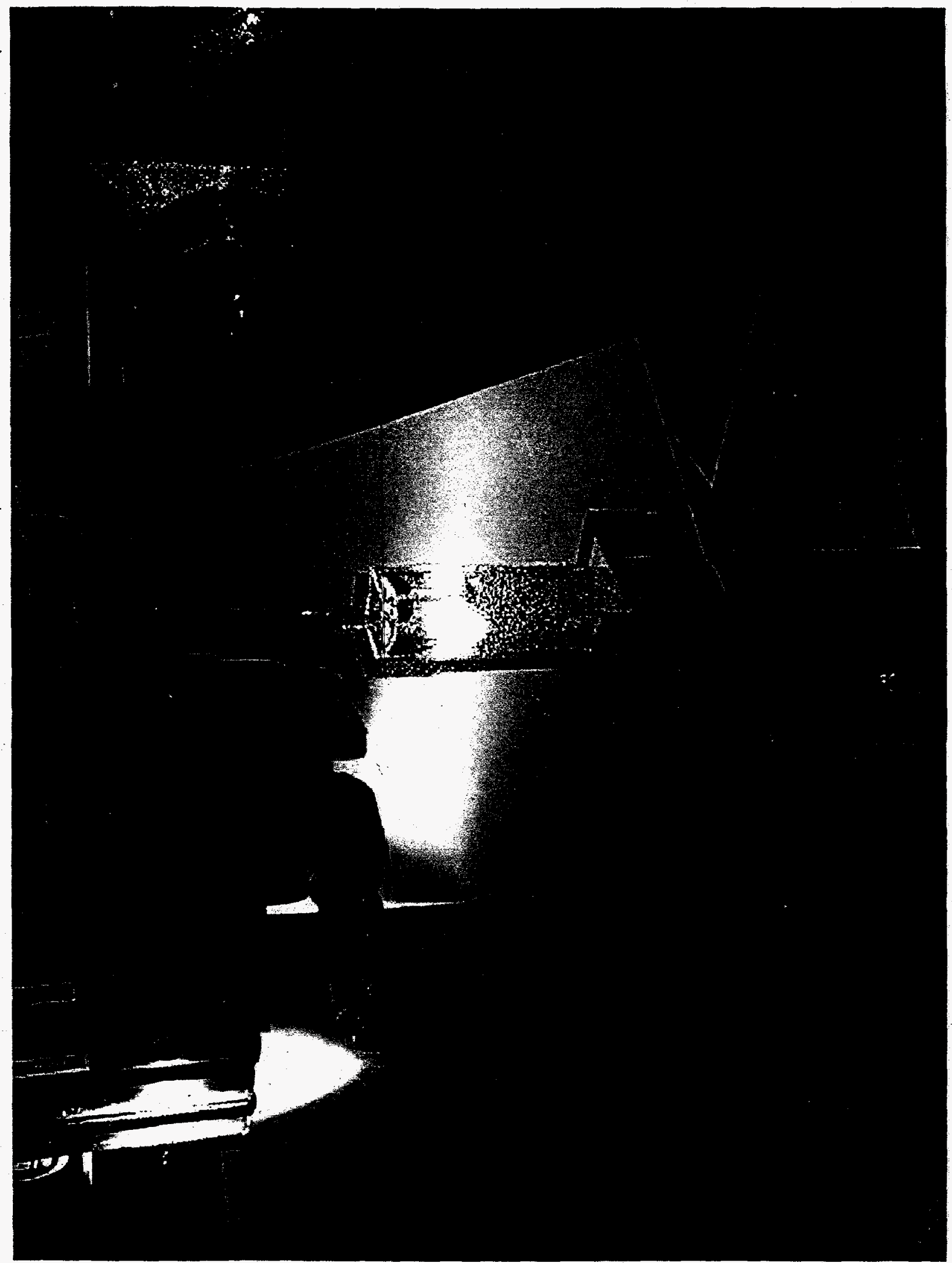




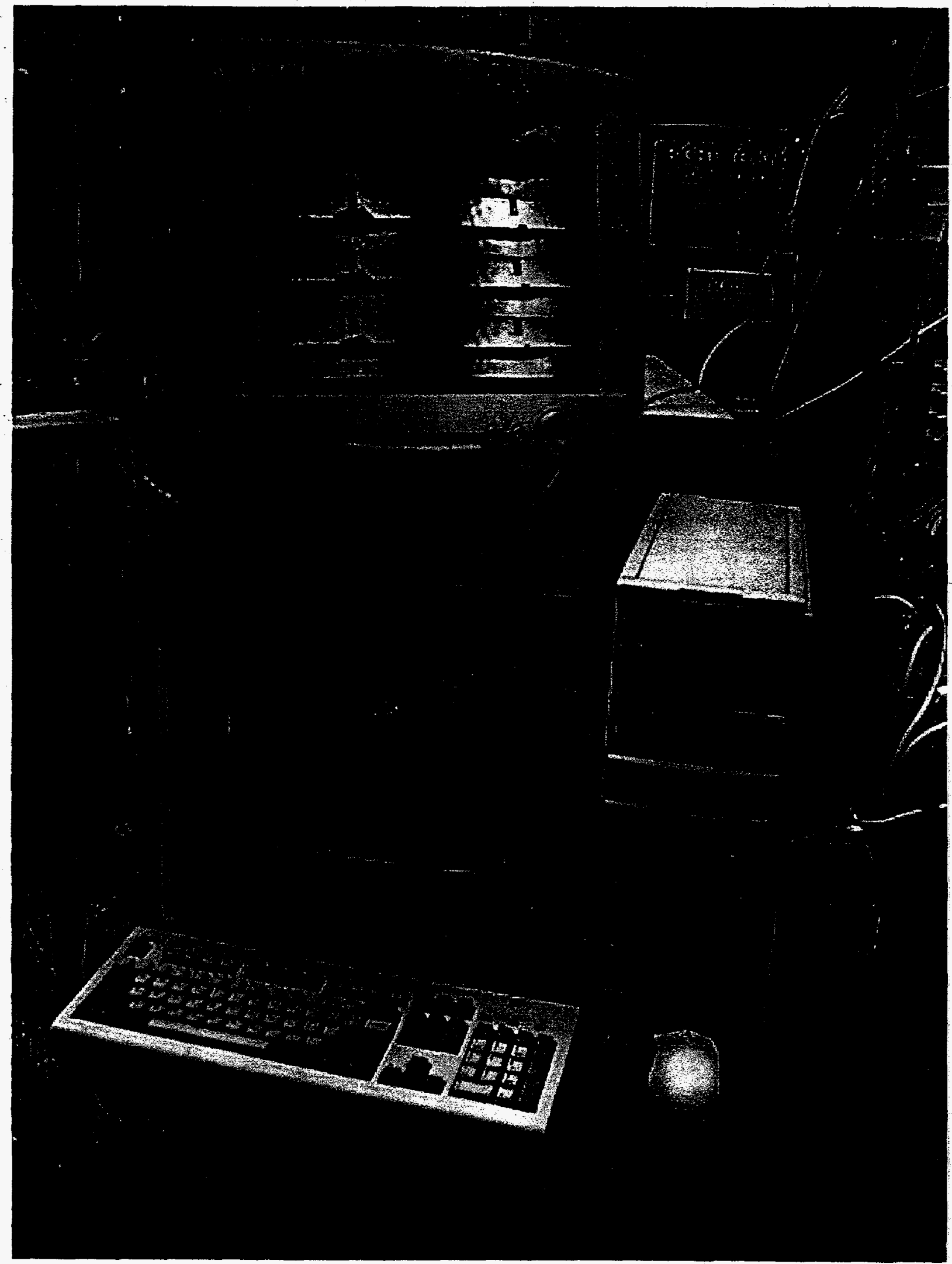


Figure 1. in vitro laser thrombolysis using OMLC, LANL, and Venous Clot materials under water
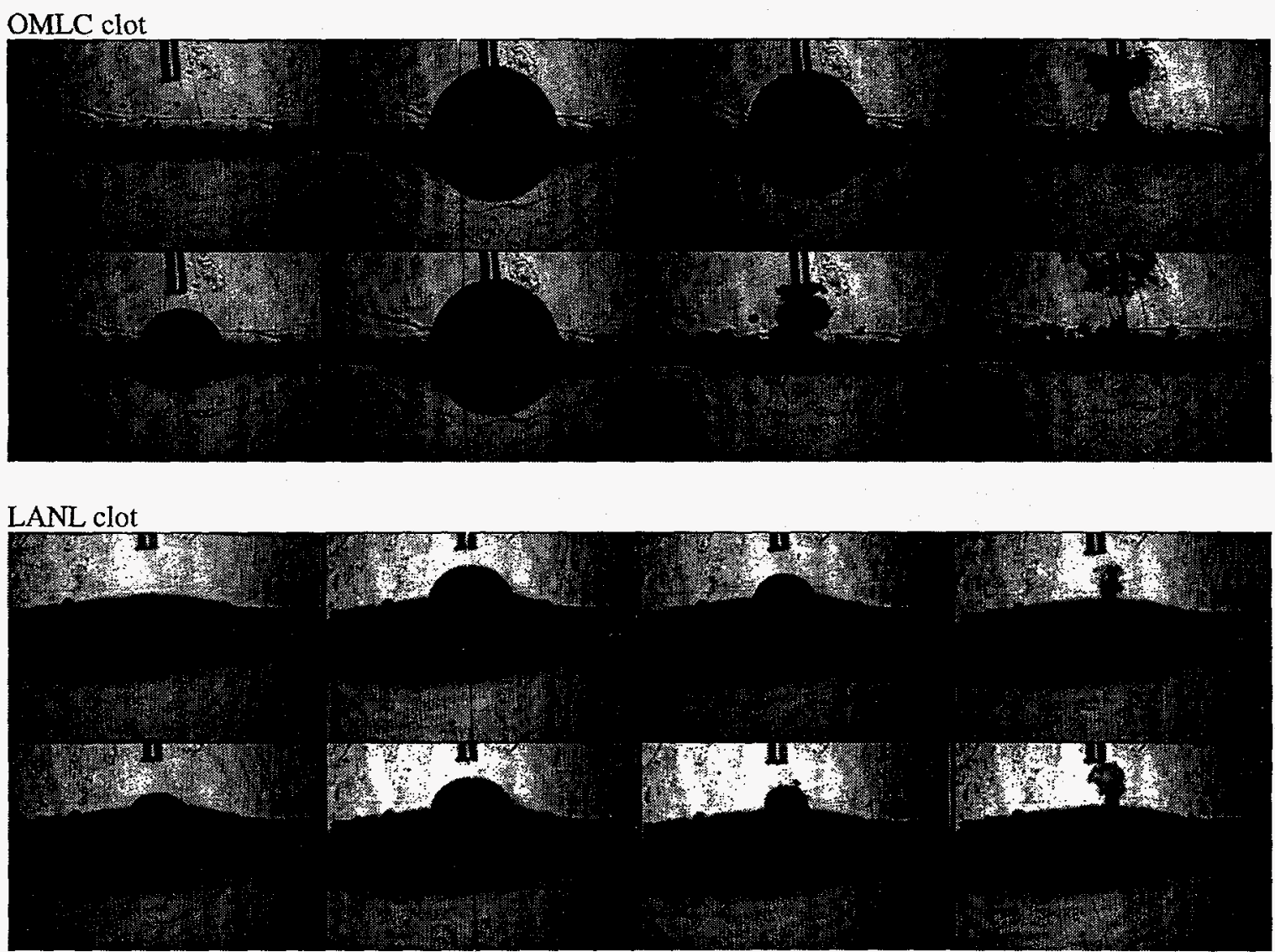

\section{Venous clot}

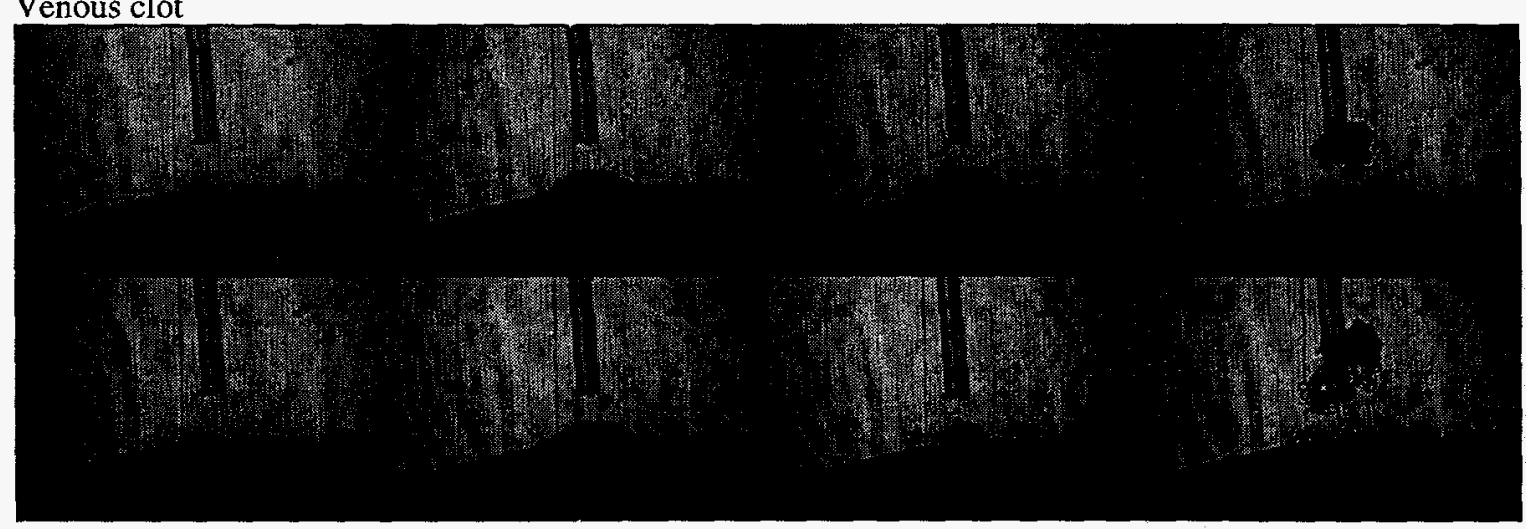


Figure 2. in vitro laser thrombolysis using OMLC, LANL, and Venous Clot materials under MD-76:water
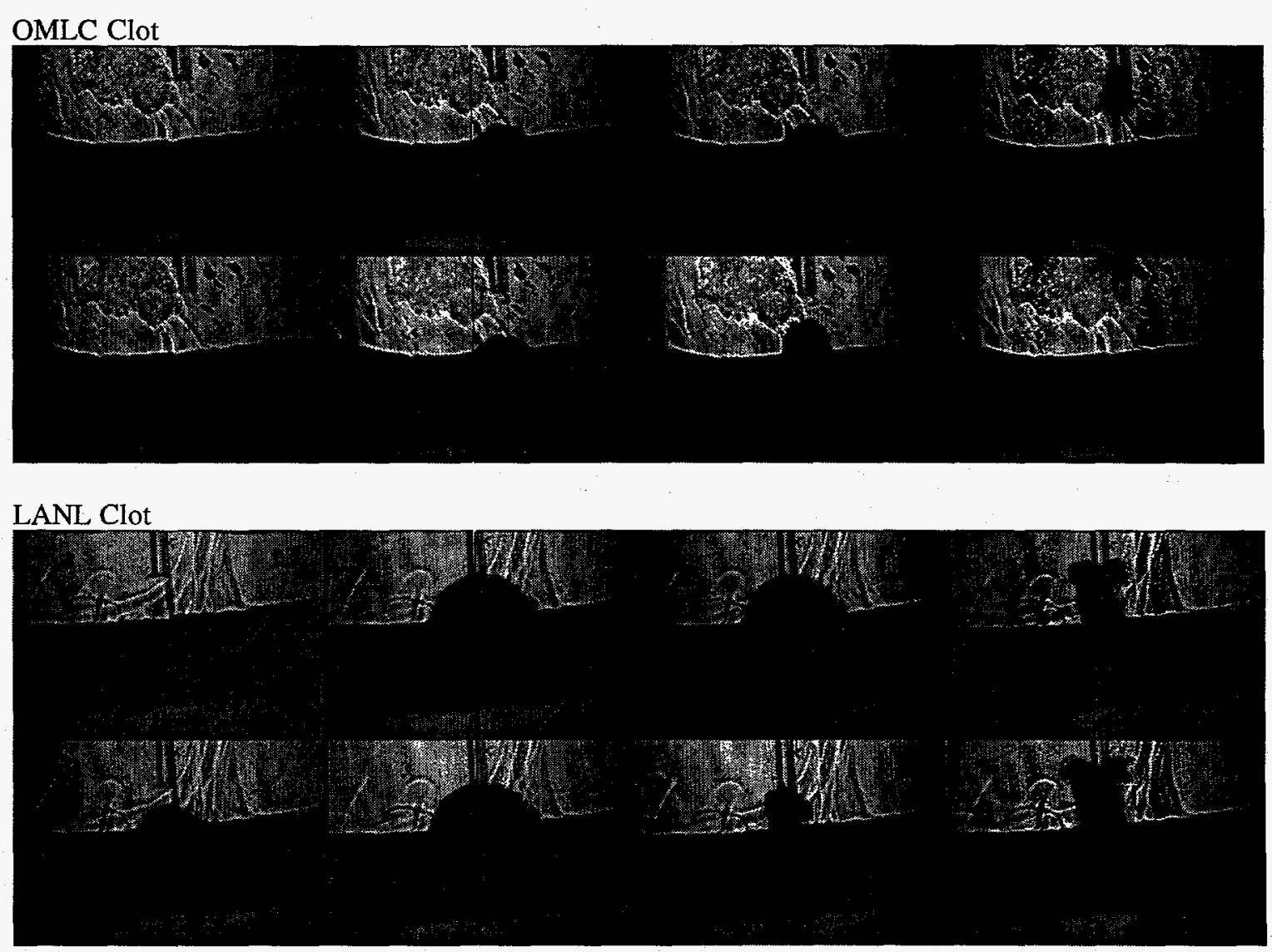

Venous Clot

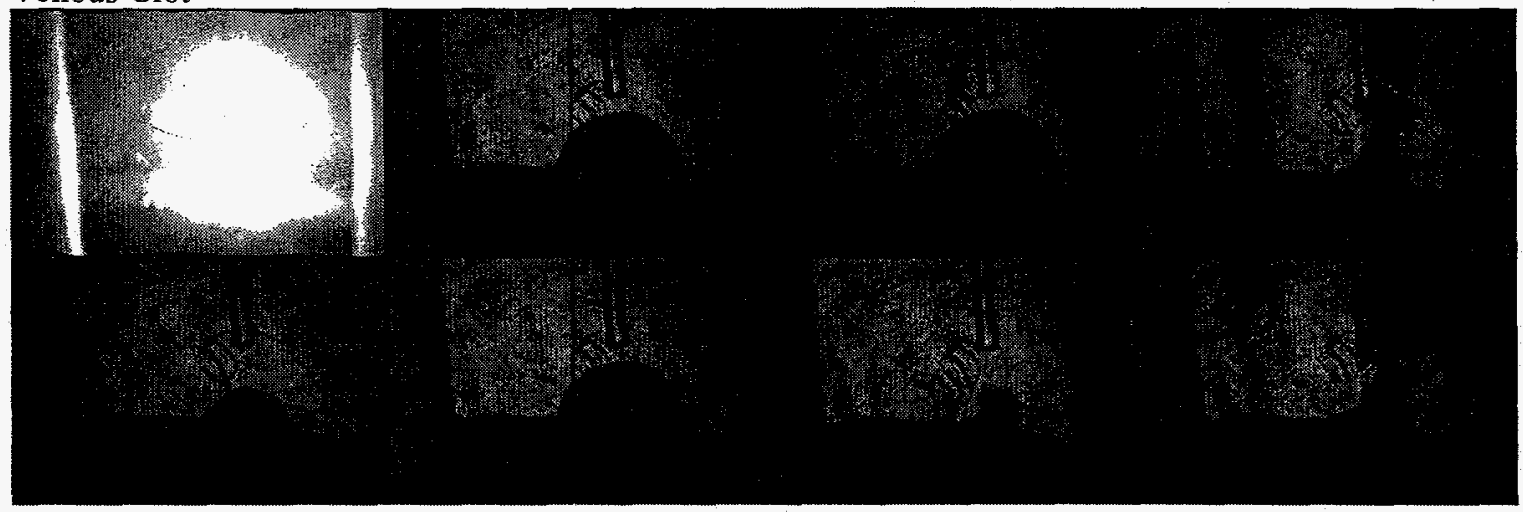


Figure 3. in vitro laser thromboly:sis using OMLC, LANL, and Venous Clot materials under mineral oil
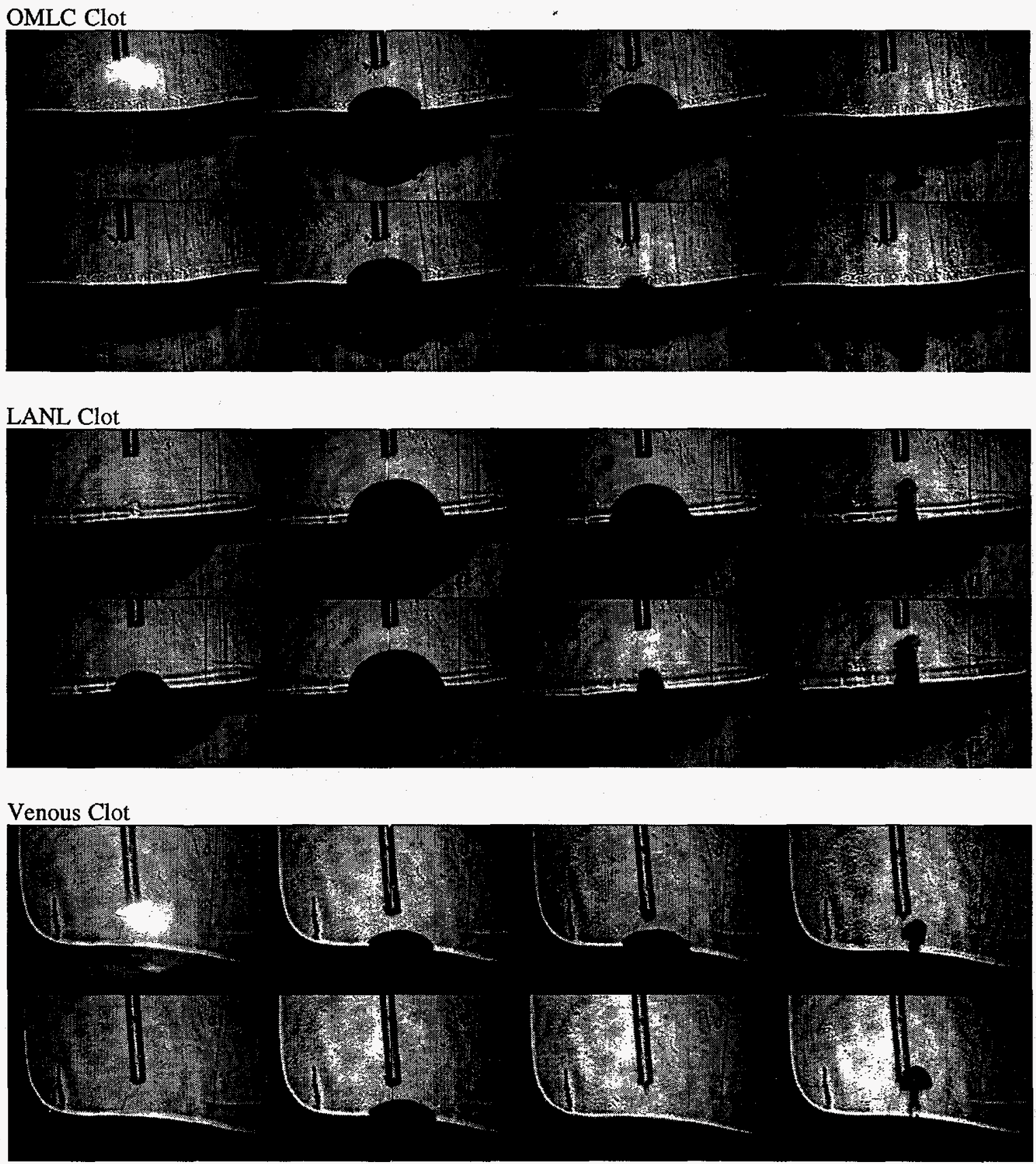
Figure 4. in vitro laser thrombolysis using OMLC, LANL, and Venous Clot materials under octane
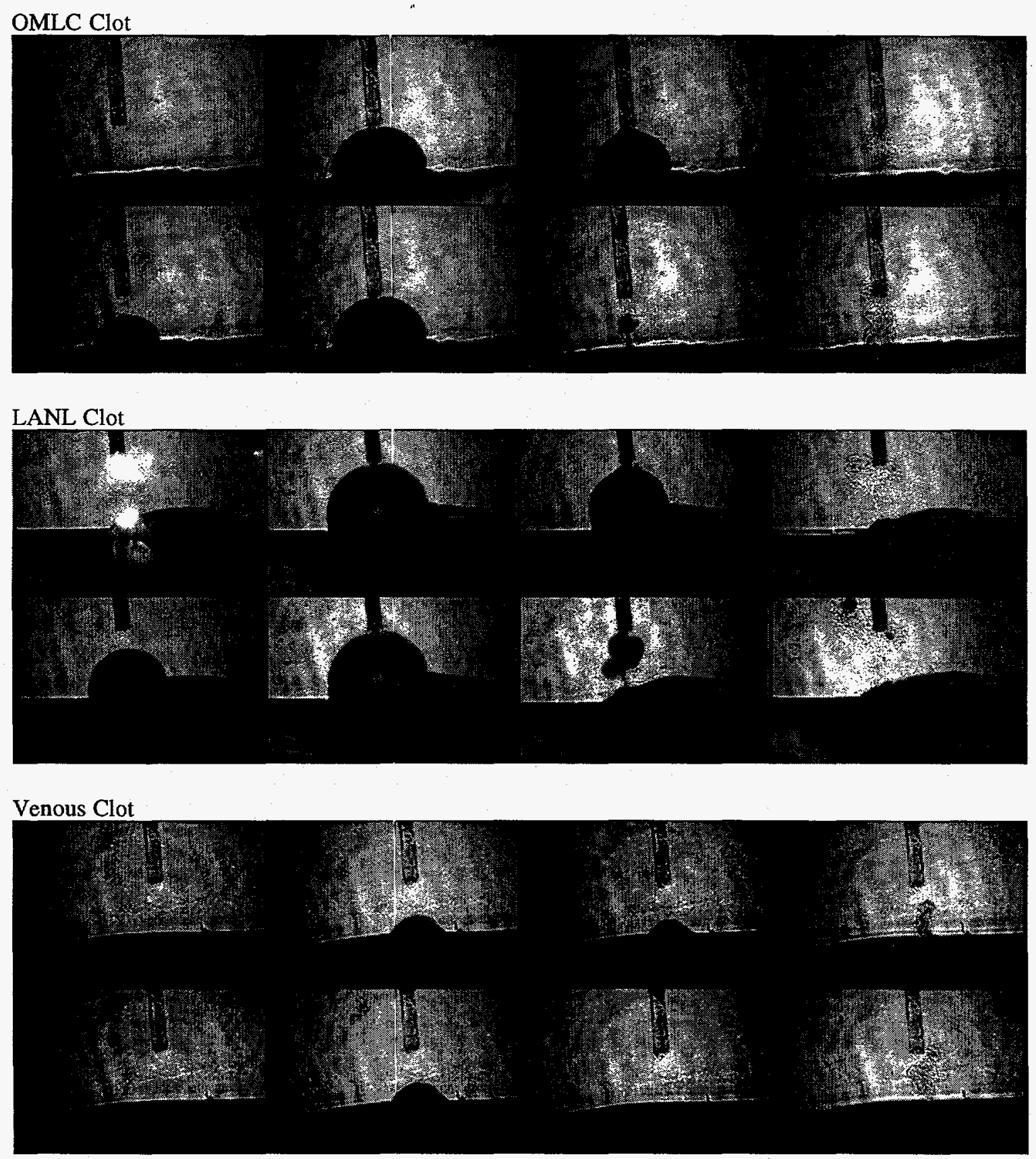


\section{Conclusions}

OMLC Clot surrogate

- bubbles seen above \& below

- amount of ablated material easily quantitated (spectro)

- bubbles consistently too large

LANL Clot surrogate

- bubbles seen only above

- amount of ablated material

not easily quantitated

- bubbles similar to real Clot

(except for octane case)

* you can even eat it!!

Venous Clot

- bubbles seen only above

- amount of ablated material not easily quantitated

- realworld? arterial clot? 